\title{
PERFORMANCE ANALYSIS OF A MEDIUM FREQUENCY OFFSHORE GRID FOR IDENTIFICATION OF VESSELS SAILING ON HIGH DENSITY MARITIME EUROPEAN ROUTES
}

\author{
Alfonso López ${ }^{1}$ \\ Miguel Gutiérrez ${ }^{1}$ \\ Andrés Ortega ${ }^{2}$ \\ Cristina Puente ${ }^{3}$ \\ Alejandro Morales ${ }^{4}$ \\ Diego Gonzalez ${ }^{4}$ \\ Emma Díaz ${ }^{2}$ \\ ${ }^{1}$ Catholic University of Ávila UCAV, Spain \\ ${ }^{2}$ University of Cantabria UC, Spain \\ ${ }^{3}$ ICAI, Pontifical Comillas University, Spain \\ ${ }^{4}$ University of Salamanca, Spain
}

\begin{abstract}
The paper analyses the performance of an Automatic Vessel Identification System on Medium Frequency (AVISOMEF), which works with the Grid Method (GM) on high density maritime European routes using real data and uniformly distributed data. Compared to other systems, AVISOMEF is a novelty, as it is not a satellite system, nor is it limited by a given coverage distance, in contrast to the Automatic Identification System (AIS), though in exceptional circumstances it leans towards it. To perform the analysis, special simulation software was developed. Moreover, a number of maritime routes along with their traffic density data were selected for the study. For each route, two simulations were performed, the first of which based on the uniform traffic distribution along the route, while the second one made use of real AIS data positioning of vessels sailing on the selected routes. The obtained results for both simulations made the basis for formulating conclusions regarding the capacity of selected routes to support AVISOMEF.
\end{abstract}

Keywords: Ships Identification Systems; Grid Method; Traffic Control Centre; SITOR

\section{INTRODUCTION}

The work described in the paper was preceded by several earlier research stages:

Firstly, in our past publications [1], [2], [3], [4], [5] we described the proposal of a new Automatic Identification System for Medium Wave Vessels (AVISOMEF). A brief synthesis of this system is given in this paper.

Next, we created a software tool which was able to simulate the analysed system, as we demonstrated in several publications [6], [7], [8]. We deal briefly with it in this aspect.
The objective of this work is was to perform a stress test of AVISOMEF and obtain reliable results concerning its operability.

To complete this objective, first we implemented the system to study an extensive, international route with adequate traffic density. It was, as shown, the route that surrounds Europe.

Next, we provided the information on the selected area to the maritime traffic data simulator. These data were of two types: uniformly distributed over an area, and obtained in real time. The obtained simulation results made the basis for formulating conclusions on the operability of AVISOMEF for the selected area. 


\section{THE AUTOMATIC IDENTIFICATION SYSTEM OF VESSELS IN MEDIUM WAVE BY THE GRID METHOD (AVISOMEF)}

The system, whose applicability to study European highdensity routes is discussed in the paper, is a result of an academic analysis of the Global Maritime Distress Safety System (GMDSS). We concluded that that system was obsolete when applying to vessels. We were aware of high investment needed and serious difficulties faced to reach world-wide agreements to remove an already existing system. So, we decided instead to improve the existing system by complementing it with new equipment which will make it a large input/output communication portal for the vessel. Combined with proper equipment and part of the already existing GMDSS equipment, it will have high potential for increasing the security and control of navigation. [2].

AVISOMEF is an automatic vessel identification system on medium frequency, MF. Compared to other systems, it is a novelty as it is neither a satellite system nor is it limited by a given coverage distance, unlike the Automatic Identification System (AIS) [9], [10], [11], though in exceptional circumstances it leans towards it.

Since the introduction of AIS, it has turned out to be an effective way of traffic control. Its only weakness is the visual range limit (more/less 30 miles), characteristic of Very High Frequency (VHF) range within which AIS works. This limit can be overcome through the use of frequencies from the High Frequency (HF) band, or by the use of some satellite-based techniques if the target does not have coverage limitations, like the system LRIT (Long-Range Identification and Tracking). The former solution is ruled out despite its global coverage, as it depends on different times of day, or even seasons. It would not be possible to reach vessels located at a smaller distance than that estimated due to the atmospheric rebound. Moreover, some side effects, like fading, for instance, could appear. The latter solution is acceptable from the technical point of view, but its disadvantage is that satellite connections are rather expensive and that the space is saturated.

AVISOMEF is the result of the symbiosis of one transmitter, four receivers - two of which include a Digital SelectiveCalling system (DSC) - and a control computer, capable of supporting a determined digital mapping that should be implemented [12].

This mapping describes the maritime area to be controlled, and has the form of a grid composed of square cells of 44 nautical miles in length (thus achieving that the two furthest points from two contiguous cells are not more distant than by 100 miles, a distance which is the medium wave propagation limit). The only condition is that the message radiated at the beginning of each cell reaches the end of the following one. The grid has one row and as many columns as needed to cover the controlled mapping area. All vessels situated on this unit surface (cell) adjust the AVISOMEF transmitters and receivers automatically in order to work in a series of channels already predetermined for each cell, corresponding to the MF frequency assigned to the Maritime
Mobile Service. The information of these channels is provided to the computer integrated into the digital mapping of the controlled area [13], [14].

The system allows the ships sailing in the area inside the squares to act as receivers - and therefore acknowledgement emitters - of a message launched from the Traffic Control Centre (TCC). But they can also work as simple repeater stations for a message that is not targeted to them, making the message advance in the grid and arrive on the ship that has been called.

To avoid conflict between possible repeaters when gaining access to the respective channel, it is important to establish a relevant criterion, for example the vessel working as a repeater is the one located further to the south and further from the following cell. Any criterion can be applicable here, the only important thing is establishing one. The waiting times are controlled by the computer from the positioning information given by the G.P.S. (Global Positioning System) or another positioning system [15].

The aim of the AVISOMEF system is to identify a ship through the radio-packet launched by the Traffic Control Centre (TCC). This radio-packet is aimed at a certain ship using its call sign, the one corresponding to the digital selective calling (DSC), Maritime Mobile Service Identity (MMSI). This radio-packet moves forward from cell to cell until a certain vessel detects that it is for it, and therefore it will not work as a repeater of the message for the ships located in the following cell in the same line. Automatically, the ship in question launches a message in the opposite direction before other ships act as repeaters. This acknowledgement moves back from cell to cell until it arrives at the receiving antenna in the Traffic Control Centre from which the initial message started.

The message included in the acknowledgement is created based on a dump from a real-time data acquisition system indicative of the state of the vessel at that time, and delivers the information related to entering or leaving the cell in which the vessel has been located.

In order to run correctly, the system should be introduced to maritime routes with traffic density of at least one ship in each cell. After several simulations performed using the static level data from the maritime traffic density in the controlled area, the system is becoming operative in the studied zone.

As mentioned above, to work properly the AVISOMEF system should be introduced to maritime routes with traffic density of at least one ship per each cell. However, if at any time there is no vessel in a cell, AVISOMEF is able to autoreset, although this situation is highly improbable. As a rule, it has to be implemented in routes with high traffic density.

The message passed from the TCC to the vessels is transmitted by the Simplex Teletype Over Radio with Forward Error Correction, SITOR-B (FEC), data communication system. This TCC sends an open collective message containing MMSI of the vessel to be located. This message also includes the MMSI of each vessel acting as a repeater in each cell, until the vessel to be located is found.

The return message from the vessel to the TCC is sent back using the SITOR with Automatic Repeat Request, SITOR-A 
(ARQ), which is a peer to peer system. This return can be done in ARQ mode, as the message, until it reaches the vessel destiny, stores the identities of all stations that have acted as repeaters, so it can establish the way back.

When sending the message, each vessel knows if it is being sent, regardless the direction of the message. If the message is sent in the SITOR - B mode, in order to identify a vessel, the system listens to the assigned working channel of the next cell to check its progress two cells beyond. If, instead, there are no vessels continuing the retransmission process, the silence is understood as a gap of vessels in the next cell (one beyond). During the message return (SITOR-A), the analysis of possible gaps in cells is more evident, as each vessel is bound to pass the confirmation message to the previous vessel.

When a gap in a cell is confirmed by the identification message, the initiated reset process includes a protocol by which the verifying station transmits the message to the vessels located two cells away in the forward direction of the message, in its channel. The minimum propagation on medium frequency (MF) in the worst weather conditions is 100 nautical miles. In warm weather, it can reach 200 nautical miles, and this amount can quadruple on a summer night. As cells are squares of 44 miles in dimension, the propagation problem is solved most of the times.

If a gap is detected during the message return, the protocol establishes sending the message again, in this case to a vessel situated two cells away from the vessel which has detected the problem. However, activation of this protocol is highly improbable, as the system is designed for routes with maritime traffic density of at least one vessel per cell, a condition which is easily fulfilled on medium density routes. For the studied routes this situation cannot occur, as they have high to very high traffic density. However, if the problem persists, the protocol will perform the same action but advancing one cell more than in the previous situation. This is to take advantage of good propagation conditions in MF.

If despite all above described measures there is still a gap of vessels, the system makes decision to use AIS, leaning on it. In this case the Traffic Control Centre (TCC) is in charge of rebuilding the communication chain, locating the first vessel approached by AIS within a maximum of 30 miles, after surpassing the gap. After this, normal operation is restored.

The number of the required channels is a double of the number of cells in each grid, and the bandwidth required for provision of working channels is below $1800 \mathrm{Khz}$, within the segment assigned to the Maritime Mobile Service. This way, the communication is not affected by undesirable phenomena like fading. The segment of the required radio spectrum is not occupied by any other system [1], [2], [16]. The used modulation is F1B or J2B (digital modulation of information systems), and in regard to the transmission rate, 100 bauds are used to be in tune with the Global Maritime Distress Security System (GMDSS).

At the end of the system description, it is noteworthy that all messages are transmitted or received through antennas located at the beginning of each row of cells. The antennas are arranged in the so-called field of antennas. In Figs. 2, 3 and 4 , these antennas are marked by points located at the centres of circular areas, indicative of the minimum coverage provided by each antenna in MF.

In our system, we outline basic aspects of electronic navigation (E-navigation):

- On-board systems that are able to integrate the information from different sensors.

- They should make use of electronic mapping in addition to electronic positioning systems, and make them appear integrated in the new systems.

- These systems will serve to improve the management of vessels traffic, by improving the support services from the ground and favouring data exchange.

- E-navigation will provide a platform for information transfer between vessels and between vessels and shorebased operators [17].

\section{SOFTWARE CAPABLE OF GENERATING THE SIMULATIONS}

The objective of the simulation software is to calculate the degree of operability of the vessel identification grid. This software allows modelling of different implementations of the AVISOMEF system, making performance calculus by means of uniformly distributed data [18] or real AIS data, along the selected maritime routes.

For the implementation of the software, we have used the architecture proposed in Figure 1. This is a client/server architecture, where the client is the simulation programme. It uses an external server, Web Map Services (WMSs) [19], [20], and a database manager system (DBMS) storing the AIS data. The WMS server provides the mapping to place the elements for the simulation via the OSM service of the standard, while the DBMS stores the maritime traffic data in the studied days. In the cases when the uniform distribution for maritime traffic routes is used, having access to the DBMS is not necessary.

The simulation software consists of four main modules:

- Mapping module, which represents all elements of the simulation.

- Representation Module, which overlaps the mapping and the layers by adding elements of AVISOMEF implementation. For that purpose, three components are used, which are:

- Maritime traffic density: obtained from the database for each time interval for which the system wants to perform the calculus, or introduced by the user as uniformly distributed data.

- Grids: elements that use the Automatic Vessel Identification System and the Grid Method (AISGM) for the division of the maritime space.

- Traffic Control Centres (TCC): each centre is in charge of one or more grids of the simulation environment.

- Calculus Module, which performs all required calculus to evaluate the performance of AVISOMEF response times, number of identified vessels, etc. 
- Event Controller Module, which enables the interaction of all user events with the application.

Depending on the user interaction with the application, the system displays a given mapping obtained from the external OSM WMS service. The user can include different elements conforming AVISOMEF, and the representation module will display both the elements of the system and the mapping where placed. Finally, when the user concludes that the implementation is correct, he performs the calculus to evaluate the performance according to the proposed design. The calculus module includes validation of the implementation, done by checking some required features of any implementation within these requirements. For example, it checks whether all grids are controlled by TCC, or whether the designed grids belong to the maritime traffic routes, etc. [6], [7] [8] [18], [21].

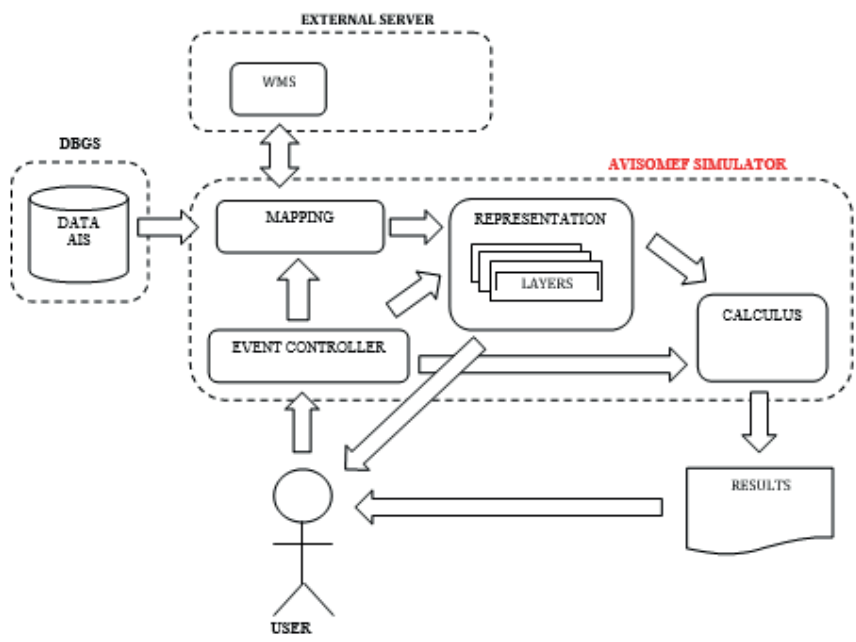

Fig. 1. Software architecture of the AVISOMEF simulator

\section{GRID IMPLEMENTATION}

Figure 2 shows in detail different segments of the European maritime route to be implemented by AVISOMEF, and their traffic densities, uniformly distributed vessels per day, being part of the route between two consecutive vertices [18].

The route selected for the analysis can be arbitrary. We have chosen this one firstly because certain density requirements that seemed a priori to be appropriate for the study were fulfilled, and secondly because of its European, international and extensive character.

The objective of the involved TCC is to identify the vessels sailing in each cell belonging to the controlled grid [3], [4], [5].

In the simulator, the layout of different grids is handlaid. However, in real cases when the system is established in a given area, the grid formation is made based on exact coordinates.

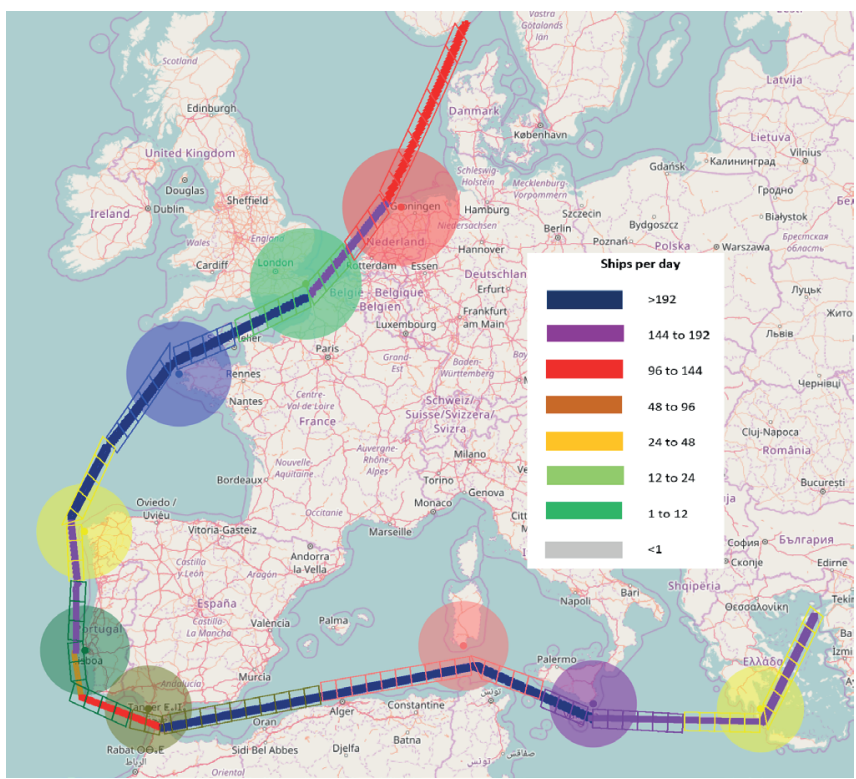

Fig. 2. European maritime routes to be implemented by AVISOMEF, indicating the traffic density uniformly distributed per segment. All segments have traffic density greater than 96 vessels/day

Figure 3 shows AVISOMEF implementation using real maritime traffic data obtained by AIS.

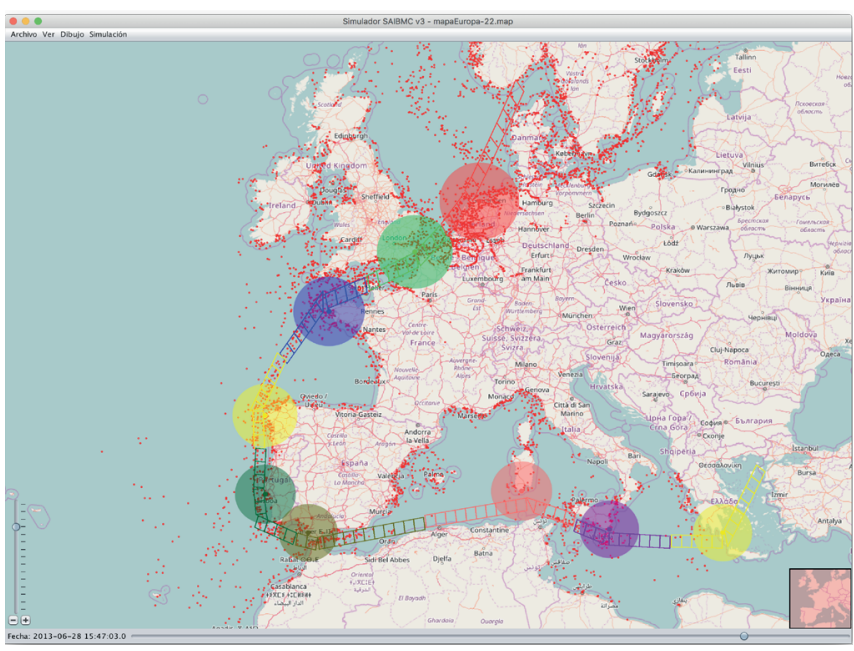

Fig. 3. First snapshot of European maritime traffic routes in which AVISOMEF is going to be implemented through non-uniformly distributed data

As seen in Figure 3, we have used nine TCC's for implementing AVISOMEF in the main European maritime routes. Each route has two grids associated to control the maritime traffic in that area. In Figure 2, TCC's are differentiated by circles of different colours, indicating the coverage area in the indicated medium wave frequency. The scope for this frequency range is 100 miles in the least favourable situations, and is larger than the dimensions of the first cell of the grid (44 miles), controlled by TCC, and covering the first cell in both directions.

Figure 3 shows a snapshot selected from thousands of them used by the simulator. It worked with 27.000 snapshots, each 
composed by hundreds of AIS data, indicative of the position of the vessels at the given time in the study area. In the North African Mediterranean route, vessels suddenly disappear and reappear near Sicily. This is because countries in that zone do not collect AIS data, or at least do not share them for monitoring. The data for this area are obtained by European receivers, thanks to good propagation conditions at that moment. This last phenomenon can be observed in Fig. 4 .

Gaps can also occur in the areas without the previously mentioned problems, for example between Finisterre and Brest, see Fig. 4, where a gap can be observed in the intermediate cells. It does not mean that there are no vessels in that area, it only means that no AIS information has been received by any receiver, as all of them are at a distance greater than 30 miles, out of the AIS range. However, in other times when the propagation is better, the same area can be full of vessels.

These are the reasons why in high density maritime routes we can find some 'hypothetical' gaps of vessels, despite knowing that there must be plenty of them at that time and area, as they are monitored before and after the gap. Obviously, not all of them end their journey at this midpoint.

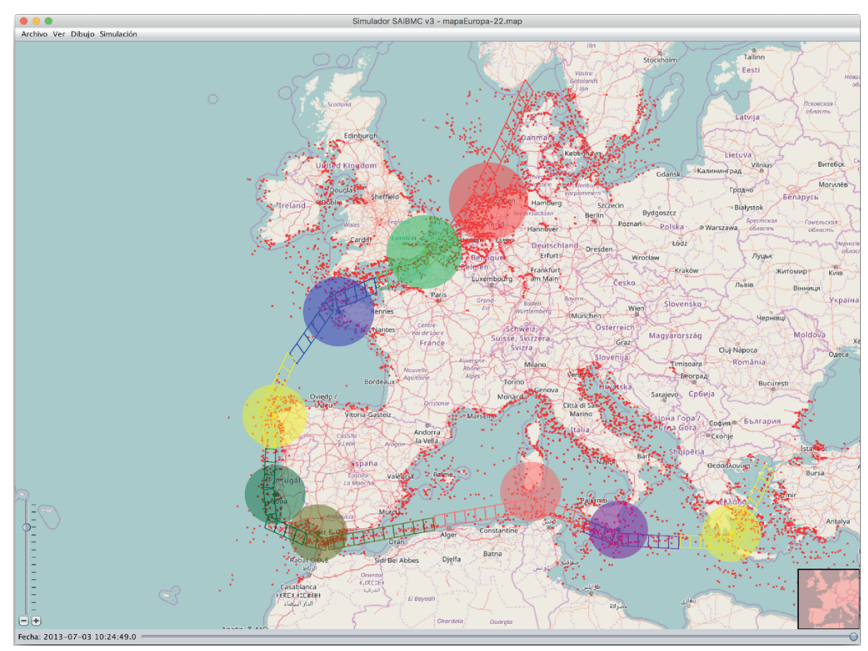

Fig. 4. Second snapshot of European maritime traffic routes in which AVISOMEF is going to be implemented through non-uniformly distributed data

\section{RESULTS}

Table 1 displays the obtained results through uniformly distributed data, beginning the analysis from TCC No. 1, which is the one located most northerly up to Rotterdam, finishing orderly with TCC No. 9 located at the south of Greece.

Each TCC has control over two previously assigned grids, built by one row of cells represented in the same colour as the belonging TCC. They are named as A and B, following the path previously explained for the TCC.
The uniformly distributed data are presented through each segment, being one of two parts of the route between two consecutive vertices.

The first column in Table 1 belongs to Traffic Control Centres (TCC), nine in all. As previously said, the first TCC is located further north, and from there, following the set direction, the second is in the English Channel, third in Brest, fourth in Finisterre, fifth in Lisbon, sixth in Cadiz, seventh in Sardinia, eighth in Sicily, and the final ninth TCC is in the south of Greece.

The second column indicates the two grids associated with each TCC. Named "A" and "B", they always follow the set direction, being first $A$ and then $B$. In this column, we can also see the number of cells per grid.

The third column displays the information about the highest traffic density in the area of interest. This column is divided into two sub-columns, one of which showing the number of vessels per day in the portion of segment controlled by the TCC, against the number of vessels per day and cell in that portion of segment. The other sub-column displays the number of vessels per day existing in the segment between two consecutive TCC's. This information is relevant as a segment is often not covered by a single TCC, but two, so this data indicates the total number of vessels existing between two consecutive vertexes (segment), as the result of addition of all vessels existing in each of the two grids composing the segment. These two grids are not controlled by the same TCC, and this situation is repeated, except for TCC No. 1, grid A and TCC No. 9, grid B, whose segments are controlled by a single TCC.

The segments in which traffic densities reach the maximum provide data regarding their minimum traffic density, but not their maximum (Fig. 2). That is why in Table 1 some cells have the message "No data on maximum density in the segment".

Noteworthy is the case of grid B associated with TCC No. 5. It is composed of more than one segment, and in this case the calculus takes into account the maritime traffic density data for the first segment, and then adds the portion of segments composing this grid.

The fourth column displays the information about the minimum traffic density in that area, following the same criteria as for the previous column.

The fifth and last column displays the operability of each grid for the maritime traffic density uniformly distributed along the segment. It was determined based upon the existence of at least one vessel per cell. 
Tab. 1. Conclusion on the operability of AVISOMEF in the routes controlled by TCC implemented by uniformly distributed data

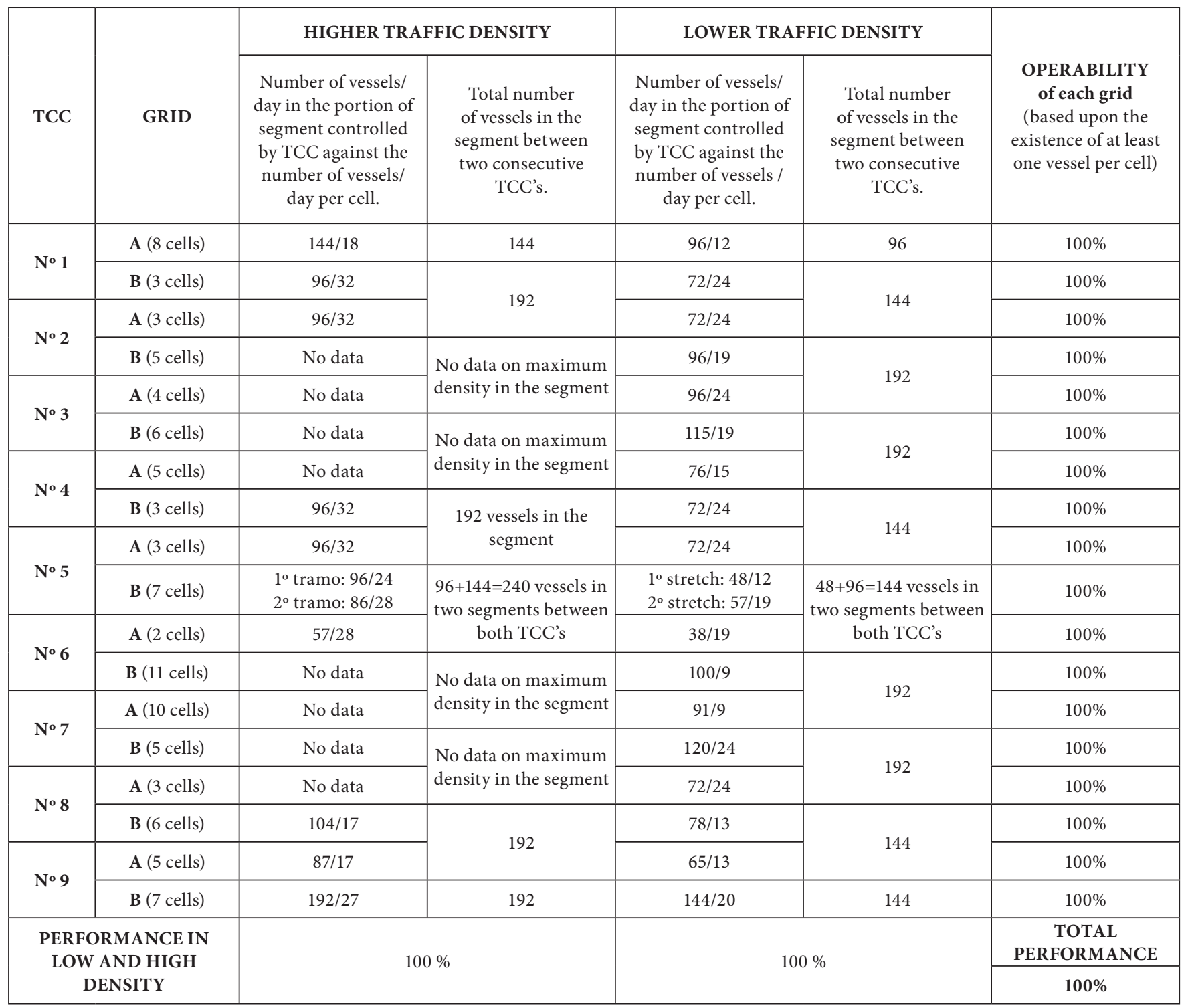

Based on these results, we can conclude that the chosen maritime routes are suitable for AVISOMEF implementation, and due to this we have performed another simulation with real data. To do so, we introduced to the AVISOMEF simulator selected pieces of AIS information, uniformly distributed throughout the year, of the six odd months of 2014 with a refresh rate of 10 minutes, in order to be representative of the total traffic in the area. The results are presented in Table 2. The maximum and minimum data of the detected targets are presented, as well as the average of all processed data. This last value is used to corroborate the conclusion previously obtained by means of uniformly distributed data and related to the operability of the system on each grid.

In Table 2, the numbers of grids are displayed that should work simultaneously in the same area to hold the existing traffic in that zone, in order to perform at least one identification per vessel and per cell. Along with this information, the numbers of channels needed for the grids to operate in the same area (double numbers of cells) are also shown.

The first column in Table 2 displays nine TCC's following the previously explained order.

The second column indicates two grids associated with each TCC. Named "A" and "B", they always follow the set direction, being first $A$ and then $B$. In this column, we can also see the number of cells per grid.

The third column shows the maximum and minimum number of vessels recorded in the grid during the studied time interval.

The fourth column displays the average of vessels per grid.

The fifth column shows the number of grids implemented in each controlled area, and the number of used channels. When the number of vessels exceeds a given value in the grid of interest, the system estimates that it is unable to give identification per vessel and per staying in cell. In this case, a second grid, identical to the first one but with different 
working channels, is automatically established. Consequently, if the number of vessels exceeds a maximum value, the system directs the next vessels entering that area to work with the first duplicated grid for that area. This way, they are monitored without excessive delays, which otherwise would lead to situations when vessels pass cells without being identified by the system in more than one occasion.

When establishing the maximum number of vessels that a grid can hold before the duplicated grid of the area starts to work, the average speed established for the vessels in that area plays an important role. As shown before, to verify whether a route is suitable for AVISOMEF, an in-depth study of the subject is required. However, if it is difficult to obtain an average speed, the best option is to set a high average speed value in the system to make sure that it functions properly. When this value is set too high, the system will just perform more identifications than needed to monitor each vessel.

When the level of maritime traffic in the area decreases, the duplicated grid is removed, redirecting the new vessels entering the zone to the original grid.

The number of channels is calculated by multiplying the number of cells of each grid by two. It is important to know how many grids assigned to each zone have been working, if it is more than one, the number of channels is to be calculated as the double number of cells multiplied by the number of grids used for the area.
As previously shown, AVISOMEF just had to activate the first duplicated grid in some occasions, just in the area controlled by TCC No. 1, grid A.

The sixth column indicates the average number of vessels existing in each grid's cell.

Based on the previous data, in the seventh and last column the established operability degree of AVISOMEF per grid is presented. $100 \%$ is not reached only in TCC No. 7, grid A. As seen before, this is the area belonging to the major North African maritime traffic routes. The traffic existing in this area is has not been monitored because the countries in this area do not collect AIS data, or at least do not share them for monitoring.

The data from vessels in this area, appearing at certain times, are collected by European receivers thanks to good propagation conditions.

Note that the other area in which monitoring of the existing traffic is incomplete, but for different reasons, is between Brest and Finisterre (TCC No. 3, grid B and TCC No. 4, grid A). Nevertheless, full operability has been obtained for this area, despite the above inconvenience.

In both situations, the system performs a linear analysis, taking into account that the input and output of the traffic have similar values. For this reason, the $100 \%$ operability is estimated in the European area, and a little lower, but still very good, in the North African zone.

Tab. 2. Conclusion on the operability of AVISOMEF in the routes controlled by TCC implemented by real data

\begin{tabular}{|c|c|c|c|c|c|c|}
\hline TCC & GRID & $\begin{array}{c}\text { MAXIMUM } \\
\text { AND MINIMUM } \\
\text { NUMBER OF } \\
\text { VESSELS IN THE } \\
\text { GRID } \\
\end{array}$ & $\begin{array}{c}\text { AVERAGE OF } \\
\text { VESSELS IN THE } \\
\text { GRID }\end{array}$ & $\begin{array}{l}\text { IMPLEMENTED } \\
\text { GRIDS AND USED } \\
\text { CHANNELS }\end{array}$ & $\begin{array}{c}\text { NUMBER OF } \\
\text { VESSELS PER } \\
\text { CELL EXISTING IN } \\
\text { EACH GRID WITH } \\
\text { AVERAGE DATA } \\
\end{array}$ & $\begin{array}{l}\text { OPERABILITY } \\
\text { of each grid } \\
\text { (based upon the } \\
\text { existence of at least } \\
\text { one vessel per cell) } \\
\end{array}$ \\
\hline \multirow{2}{*}{ No 1} & A (8 cells) & $123 / 38$ & 79 & $2 / 32$ & 9 & $100 \%$ \\
\hline & B (3 cells) & $120 / 69$ & 95 & $1 / 6$ & 31 & $100 \%$ \\
\hline \multirow{2}{*}{ No 2} & A (3 cells) & $129 / 70$ & 96 & $1 / 6$ & 32 & $100 \%$ \\
\hline & B (5 cells) & $166 / 93$ & 135 & $1 / 10$ & 27 & $100 \%$ \\
\hline \multirow{2}{*}{$\mathrm{N}^{\circ} 3$} & A $(4$ cells $)$ & $119 / 48$ & 88 & $1 / 8$ & 22 & $100 \%$ \\
\hline & B (6 cells) & $113 / 6$ & 36 & $1 / 12$ & 6 & $100 \%$ \\
\hline \multirow{2}{*}{$\mathrm{N}^{\circ} 4$} & A (5 cells) & $52 / 15$ & 27 & $1 / 10$ & 5 & $100 \%$ \\
\hline & B (3 cells) & $40 / 28$ & 27 & $1 / 8$ & 9 & $100 \%$ \\
\hline \multirow{2}{*}{ No 5} & A (3 cells) & $37 / 26$ & 31 & $1 / 6$ & 10 & $100 \%$ \\
\hline & B (7 cells) & $62 / 43$ & 53 & $1 / 14$ & 7 & $100 \%$ \\
\hline \multirow{2}{*}{ No 6} & A ( 2 cells $)$ & $31 / 10$ & 16 & $1 / 4$ & 8 & $100 \%$ \\
\hline & B (11 cells) & $106 / 49$ & 71 & $1 / 22$ & 6 & $100 \%$ \\
\hline \multirow{2}{*}{$\mathrm{N}^{\circ} 7$} & A (10 cells $)$ & $24 / 0$ & 9 & $1 / 20$ & 0,9 & $90 \%$ \\
\hline & B (5 cells) & $80 / 22$ & 37 & $1 / 10$ & 7 & $100 \%$ \\
\hline \multirow{2}{*}{ No 8} & A (3 cells) & $83 / 22$ & 39 & $1 / 6$ & 13 & $100 \%$ \\
\hline & B (6 cells) & $67 / 1$ & 19 & $1 / 12$ & 3 & $100 \%$ \\
\hline \multirow{2}{*}{ No 9} & A ( 5 cells $)$ & $17 / 5$ & 11 & $1 / 10$ & 2 & $100 \%$ \\
\hline & B (7 cells) & $64 / 0$ & 35 & $1 / 14$ & 5 & $100 \%$ \\
\hline
\end{tabular}




\section{CONCLUSIONS AND FUTURE RESEARCH}

To conclude, we can state that it is possible to establish traffic control by means of AVISOMEF for the selected European maritime routes, with the highest degree of operability.

This implies that we can establish a real-time control without using satellite techniques. This control is much cheaper, and automatic, for more than $90 \%$ of vessels sailing throughout European routes. It can be extended to a large number of vessels identified by the system and their surroundings, being previously detected by electronic devices located onboard.

Finally, it is important to state that there are more possibilities to explore Radio Systems installed aboard vessels. As demonstrated, little-changes open up possibilities to set up a new system to help navigation. The next step will be analysing the worldwide maritime routes, to select those that, by their traffic density, are able to support the system and allow its proper implementation.

\section{REFERENCES}

1. A. López, A. Ortega, M. Gutiérrez, F. Blanco, C. Puente, "Automatic identification system of vessels using the grid method", Journal of Maritime Research, vol. 9, no. 1, pp. 71-76, 2012.

2. A. López, "Planteamiento de un nuevo sistema, resultado de la interacción de GMDSS con otros dispositivos", Academica Española, 2012.

3. A. López, M. Gutiérrez, A. Ortega, F. Blanco, M. Graña, "Proposal of a medium frequency offshore grid for identification of vessels sailing in high density maritime Spanish routes", OCEANS 2011 IEEE - Spain. 2011.

4. A. López, M. García, F. Herráez, F. Blanco, "Análisis medioambiental derivado de un control en tiempo real de las rutas marítimas españolas fundamentales", CONAMA 10 Congreso Nacional del Medio Ambiente, 2010.

5. A. López, M. Gutiérrez, F. Herráez, “Constitución de una red marítima en onda media capaz de albergar el tráfico necesario para la identificación de buques que naveguen por rutas canarias". XVIII Congreso Nacional de Ingeniería Mecánica, 2010.

6. M. Gutiérrez, A. López, A. Morales, V. Carro, "Arquitectura software para el desarrollo de aplicaciones de control de tráfico marítimo", $6^{a}$ Conferência Ibérica de Sistemas e Tecnologias de Informação, 2011.

7. M. Gutiérrez, "Aplicación de modelado de un sistema de identificación de buques”, Académica Española, Madrid. 2011,
8. M. Gutiérrez, A. López, F. Herráez, C. Puente, S. Zubelzu, "Aplicación para el estudio de implantación de un sistema no satelitario de identificación de buques", Revista Iberoamericana de Automática e Informática industrial, vol. 9, pp. 244-248, 2012.

9. G.K. Høye, T. Eriksen, B.J. Meland, B.T. Narheim, "Spacebased AIS for global maritime traffic monitoring", Acta Astronautica, vol. 62, no. 2-3, pp. 240-245, 2008.

10. K. Inoue, H. Usui, K. Hirono, W. Sera, “A ship monitoring system using a communication satellite for maritime safety", Maritime Security and MET, pp. 205-217, 2005.

11. J.L. Larrabel, M.A. Gómez, I. Sotés, F.J. Alvarez, M.C. Rey, V.E. Mielgo, I. Sotes, Basogain, "Vessel condition monitorization through satellite using principal X. component analysis", Journal of Maritime Research, vol. 7, no. 3, pp. 3-14, 2010.

12. R. Hekmat, P. Van Mieghem, "Connectivity in wireless ad-hoc networks with a log-normal radio model”, Mobile Networks and Applications, vol. 11, no. 3, pp. 351-360, 2006.

13. I.F. Akyildiz, X. Wang, W. Wang, "Wireless mesh networks: A survey", Computer Networks, vol. 47, no. 4, pp. 445-487, 2005.

14. Y. Ge, P. Kong, C. Tham, J.S. Pathmasuntharam, "Connectivity and route analysis for a maritime communication network", 6th International Conference on Information, Communications and Signal Processing, ICICS, 2007.

15. A. López, "La medida del tiempo. Un aliado para conseguir una relación más sostenible entre el tráfico marítimo, el medio ambiente y la economía”, IX Congreso Nacional del Medio Ambiente (CONAMA IX), pp. 978, 2009.

16. P. Santi, D.M. Blough, "The critical transmitting range for connectivity in sparse wireless ad hoc networks", IEEE Transactions on Mobile Computing, vol. 2, no. 1, pp. 25-39, 2003.

17. D. Patraiko, "The Development of e-Navigation", International Journal on Marine Navigation and Safety of Sea Transportation, vol. 1, no. 3, pp. 257-260, 2007.

18. United States Coast Guard, "Amver Density Plot Display". Available: http://www.amver.com/Reports/DensityPlots. 2017, May, 15.

19. United Nations, Statistical Division 2000, "Handbook on Geographic Information Systems and Digital Mapping”. Homepage of United Nations Publications, On line. Available: http://unstats.un.org/unsd/publication/SeriesF/ SeriesF_79E.pdf. 2011, March,15. 
20. Open Geospatial Consortium (2006), OpenGIS@ Web Map Server Implementation Specification. Available: http:// www.opengeospatial.org/standards/wms. 2017, May, 15.

21. S. Wen, P. Kong, J. Shankar, H. Wang, Y. Ge, C. Ang, "A novel framework to simulate maritime wireless communication networks”, Oceans Conference Record (IEEE), 2007.

\section{CONTACT WITH THE AUTHORS}

\author{
Alfonso López \\ Catholic University of Ávila UCAV \\ SPAIN \\ Miguel Gutiérrez \\ Catholic University of Ávila UCAV \\ SPaIN \\ Andrés Ortega \\ University of Cantabria UC \\ SPAIN \\ Cristina Puente \\ ICAI, Pontifical Comillas University \\ SPAIN
}

Alejandro Morales

University of Salamanca

SPAIN

Diego Gonzalez

University of Salamanca

SPAIN

Emma Díaz

University of Cantabria UC

SPAIN 